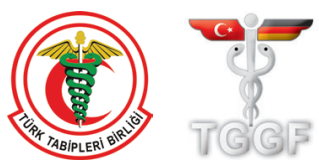

\title{
New insights on the pathogenesis of endometriosis and novel non-surgical therapies
}

\author{
(D) Anom Suardika, (D) Tjokorda Gede Astawa Pemayun \\ Department of Obstetrics and Gynecology, Udayan University, Sangah Hospital, Bali, Indonesia
}

\begin{abstract}
Endometriosis is a disease of theories, but none has succeeded to explain the whole picture. Most widely available drugs for endometriosis aim to relieve symptoms and improve fertility. Unfortunately, many short and long-term side-effects are associated with the treatments. To overcome this problem, researchers have developed many novel therapeutic agents, including non-invasive technique. We aim to provide new insights on pathogenesis model and novel non-surgical treatments for endometriosis, including drugs already available in the market and also drugs which are still under research. Seven novel treatment modalities are recognized, namely dienogest, aromatase inhibitor (AI), gonadotrophine-releasing hormone (GnRH) antagonist, anti tumor necrosing factor (TNF)- $\alpha$, selective estrogen receptor modulator (SERM), selective progesterone receptor modulator (SPRM), and high-intensity focused ultrasound (HIFU). Dienogest, AI, and GnRH antagonists are effective novel treatments with good tolerance and safety. SERM and SPRM show inconsistent results, while anti-TNF- $\alpha$ is still in the animal experimental stage. HIFU is a potential futuristic treatment. However, it is still a long way until this technology is truly applicable. (J Turk Ger Gynecol Assoc 2018; 19: 158-64)
\end{abstract}

Keywords: Endometriosis, novel therapy, non-invasive

Received: 27 June, 2018 Accepted: 16 July, 2018

\section{Impacts of Practice}

- Knowledge on new pathogenesis and pathophysiologic models of endometriosis may modify clinicians' perspective on therapy

- Implementing new therapeutical options may help to improve patients' satisfaction

\section{Introduction}

Endometriosis is an estrogen-dependent chronic inflammatory disease associated with chronic pelvic pain and infertility. Endometriosis causes a wide spectrum of symptoms and inflicts heavy socio-economic burden to patients. Endometriosis occurs in about $2-10 \%$ of women of reproductive age $(1,2)$ and approximately in $50 \%$ of infertile women (3). The economic burden was reported 69,4 billion dollars in United States every year $(4,5)$.

Clinical diagnosis of endometriosis is often difficult due to the wide spectrum of symptoms which most are non-spesific.
Visual observation through laparoscopy and hystopathological sampling are the gold-standards $(2,6)$. The most common complaints in endometriosis patients are dysmenorrhea (79\%) and chronic pelvic pain (69\%) (1). Many theories have been proposed as the basis for medical treatment (7-10). Conventional medical treatments include progesterone, danazole, combined oral contraceptive (COC), gonadotrophine-releasing hormone (GnRH) agonist, and non-steroid anti-inflammatory drugs (NSAIDs). The aim of these conventional therapies are suppression of inflammatory reaction, reduction of serum estrogen level, or increasing serum progesterone level $(1,9,10)$. The efficacies of conventional therapies are good, but when given for a longer period, some aspects should be considered: 1) significant potential side-effects, especially for reproductiveaged women as the result of hipoestrogenic environment; 2) high relapse rate despite optimal medical therapy, and 3) costly treatments $(9,10)$. Along with the massive development in the etiopathogenesis theories, many treatment modalities emerge, aiming at specific molecular mechanism and to avoid 
previous generations of drugs'side-effects $(1,11)$. In this paper, we present novel therapies for endometriosis and their specific mechanisms of action.

\section{Overview of Endometriosis Pathogenesis}

Among existing theories on endometriosis pathogenesis, Sampson's retrograde menstruation theory is the most popular, because it is scientifically proven, easy to understand and widely acceptable. The theory is supported by laparoscopic findings from women on perimenstrual period, of which menstrual blood components were found in peritoneal cavity on $90 \%$ of patients (12-15). In 1960s, Ferguson proposed that mesothelial cells from peritoneal and ovarian surfaces may undergo metaplasia and transform into endometrial tissue (12,15-17). Consistently, mullerian remnant theory also describes that primordial cells spread accross posterior pelvic wall may transform into endometrial tissue when exposed to high-level estrogenic stimulus $(12,16)$. Stem cell potential to differentiate into endometrial tissue under hyperesterogenic influence has also been studied $(15,18)$.

In endometriosis, various biomolecular changes are involved in the development of lesions, including: impaired immune system response, increased cytokines and pro-inflammatory mediators, increased angiogenic activity, excessive estrogen production, and progesterone resistance. Ectopic tissues may avoid normal apoptotic and phagocytosis mechanisms, presumably due to decreased expression of metalloproteinases, CD36 and increased production of dissolved intercellular adhesion molecule-1 (19).

Increased inflammatory activity is also present in endometriosis, through the overproduction of Interleukin (IL)1, IL-6, IL-8, monocyte chemo-attractant protein-1, RANTES, tumor necrosis factor (TNF)- $\alpha$ and TNF- $\beta$. These mediators will further stimulate the prostaglandins production and triggers the release of vascular endothelial growth factor that serves as proangiogenic agent (19).

The most important factor in the pathophysiology of endometriosis is the estrogen hormonal dysregulation and progesterone resistance. Hypomethylation of the $\mathrm{CpG}$ cluster changes the balance of estrogen receptors, from alpha subtypes $(\mathrm{ER} \alpha)$ dominance into beta subtypes (ER $\beta)$ dominance. In endometrial tissue, ER $\beta$ binds to the promoter of $\mathrm{ER} \alpha$, suppressing the production of $\mathrm{ER} \alpha$, thereby reducing the formation of progesterone (PR) receptor, resulting in resistance to progesterone. ER $\beta$ regulates cell cycle progression, and contributes to the proliferation of endometriotic cells $(20,21)$. Prostaglandins are also known to increase the activity of steroidogenic proteins especially aromatase (p450arom) and the production of tissue estrogens, thereby aggravating the condition $(22,23)$. We can see the summary of biomolecular process of endometriosis in Figure 1.

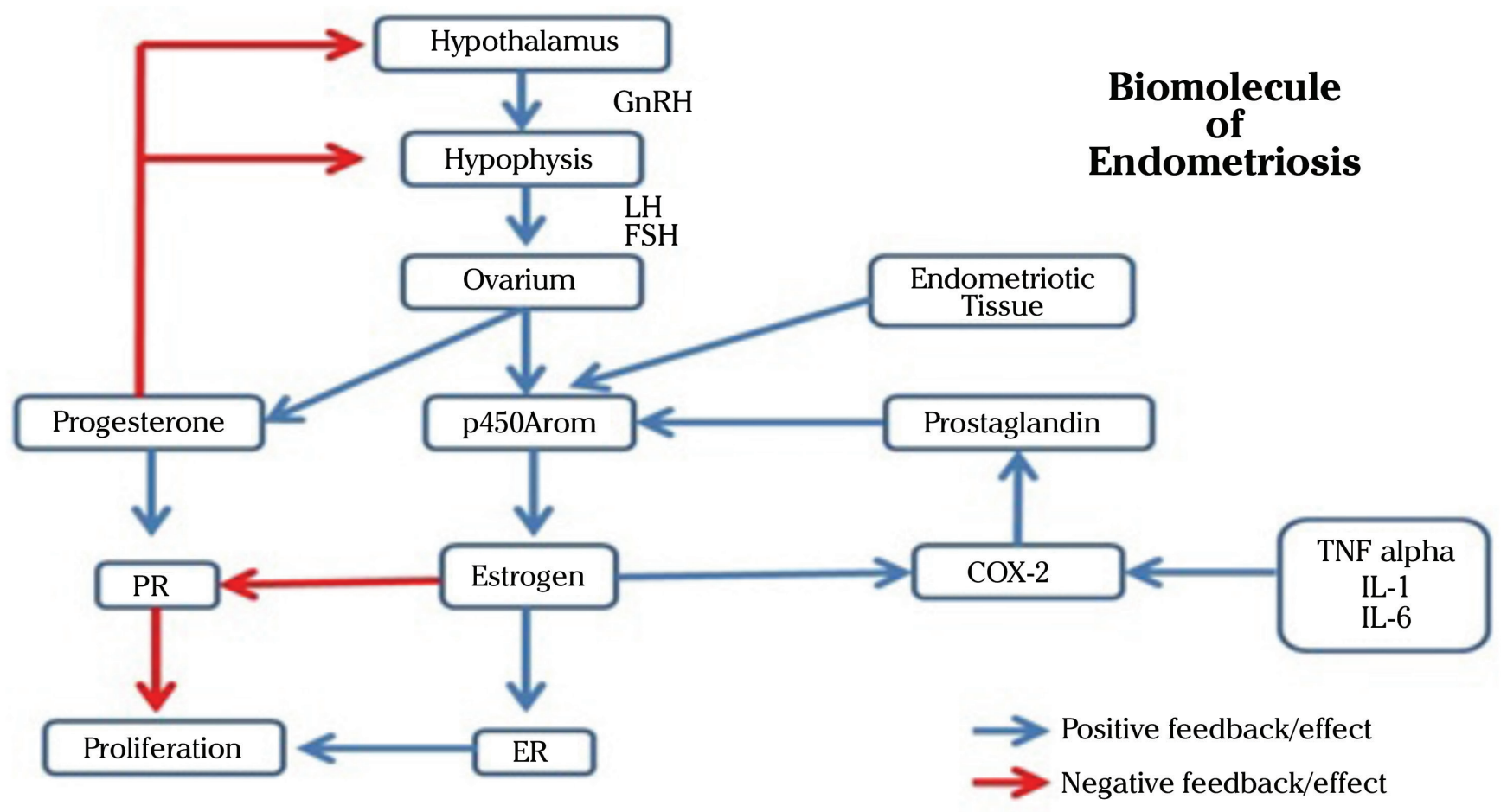

Figure 1. Biomolecular processes in endometriosis

PR: Progesterone receptor; ER: Estrogen receptors; IL: Interleukin; COX: Cyclooxygenase; LH: Luteinizing hormone; FSH: Follicle-stimulating hormone, GnRH: Gonadotrophine-releasing hormone; TNF: Tumor necrosing factor 
An understanding of the biomolecular processes in endometriosis has now brought about the possibility of potential new therapies. These new therapies aim specific pathophysiologic mechanisms that have not been targeted by conventional methods. Although promising, some has not been fully tested in humans, and some are still in the early phase of clinical trials $(24,25)$.

\section{Novel Medical Therapies}

\section{Dienogest}

Dienogest (DNG) is an oral progestin that has been recognized as single-drug therapy for endometriosis in Europe, Japan, Australia and Singapore (26,27). DNG is a 19-nortestosterone derivative with the advantage of short plasma half-life, strong progestin effect on endometrium, high bioavailability, antiandrogenic activity, and moderate gonadotropin secretion inhibition, with no interference with p450 cytochrome in the liver $(28,29)$. Inhibition of gonadotropin secretion is not as high as $\mathrm{GnRH}$ agonist, with mean estrogen level maintained at 30-60 $\mathrm{pg} / \mathrm{mL}(28)$.

DNG $2 \mathrm{mg} /$ day has been shown to significantly inhibit the expression of genes and proteins associated with aromatase and cyclooxygenase (COX)-2, as well as prostaglandin E2 (PGE2) production (30,31). DNG administration also increases the $\mathrm{PR}-\beta / \mathrm{PR} \alpha$ ratio, as well as decreases the $\mathrm{ER} \beta / \mathrm{ER} \alpha$ ratio; thus, minimizing progesterone resistance in endometriosis patients (32). Provision of long-term DNG has been proven to be effective, safe, tolerable, as well as low incidence of adverse events and drop-out rates (26,33). DNG administration, when compared to GnRH agonists, provides a similar improvement in the intensity of complaints, but lower decrease in estrogen level or negative impact on bone mass (26). DNG can be tolerated in long-term administration due to negligible antiestrogenic, glucocorticoid, and mineralocorticoids effects $(26,29)$. The most frequent side effects are breast pain (4.2\%), nausea (3.0\%), and irritability $(2,4 \%)(27,34)$.

\section{Aromatase inhibitor}

The administration of aromatase inhibitors (AI) in endometriosis patients may directly decrease aromatase activity in endometriotic tissue and estrogen level, thereby suppressing COX-2 activity, decreasing PGE2 level, and breaking the positive feedback loop (35-38). When given to premenopausal women, AI suppresses estrogen production and increases the follicle stimulating hormone (FSH) production by the pituitary gland; dosage of $0.5 \mathrm{mg}$ decreases estrogen up to $97-99 \%$ (35). The third-generation Als are selective, reversible, and potent triazole derivatives, making it suitable for use in clinical practice (35). The recommended daily dose is $1 \mathrm{mg}$ for anastrozole, $2.5 \mathrm{mg}$ for letrozole and $25 \mathrm{mg}$ for exemestane, with the lowest decrease in E2 levels caused by exemestane (52-72\%) (39). AIs when combined with progestogen, $\mathrm{COC}$, or $\mathrm{GnRH}$ agonist significantly decrease endometriotic pain intensity, thereby improving patient's quality of life. $\mathrm{AI}$ is superior in preventing postoperative recurrence when compared to GnRH or Danazol, within 6 months period $(40,41)$. AI is equivalent to clomiphene citrate in increasing pregnancy rates (42). In post-menopausal patients, AI shows exellent performance (43). Side effects are mostly mild (ie mild headache, joint pain or stiffness, nausea, diarrhea, hot flashes, mild bone density decrease) $(40,41)$.

\section{GnRH antagonist}

GnRH antagonists act by competitively block GnRH receptor. When compared to GnRH agonist, this class of drugs shows noflare period, faster therapeutic onset, and unchanged pituitary sensitivity to $\mathrm{GnRH}$ after discontinuation of therapy (44-48). Single dose elagolix of 25-400 mg will decrease luteinizing hormone up to $22-35 \%$, FSH $62-71 \%$, and estradiol $42-65 \%$ (46). Administration of Elagolix $150 \mathrm{mg}$ per day (75 mg twice daily) improves pelvic pain as measured with Biberoglu and Behrman pain scale, comparable to DMPA injection (47). The highest improvement on patient's quality of life as measured by Endometriosis Health Profile- 5 attained at dosage $150 \mathrm{mg}$ per day $(49,50)$.

The most common side effects are hot flush, nausea and headache. With long-term use up to 6 months, these side effects are increased by $10 \%$. Approximately $25 \%$ of patients become amenorrhea after 8 weeks of therapy with a dose of $150 \mathrm{mg}$ per day, but this number decreases to $7.6 \%$ after 24 weeks (44). Elagolix causes a mild decrease in axial bone density $(44,47)$. The rate of pregnancy increases by $5 \%$ at a dose of $150 \mathrm{mg}$ per day (47). No teratogenic effect was found from elagolix treatment (44).

\section{Anti-TNF- $\alpha$}

As noted earlier, TNF- $\alpha$ has a major role in the pathogenesis and survival of endometriosis lesions. Thus, targeting this molecule is a rational approach to treat endometriosis. Drugs classified as anti-TNF- $\alpha$ are either monoclonal antibodies (infliximab) or soluble TNF- $\alpha$ receptors (etanercept, TNF recombinant human protein bindings) (51-53). In baboons, anti-TNF- $\alpha$ inhibits the development of lesions significantly, but fails to increase pregnancy rates, fecundity levels per cycle, time to pregnancy, and cumulative pregnancy rates $(54,55)$. In vitro studies have shown that regression of lesion 
size, as well as decreased expression of inflammatory cytokines after anti-TNF- $\alpha$ administration (56-61). Mild sideeffects may include headache and allergic reactions during intravenous administration, whereas long-term administration is associated with serious infections and tuberculosis reactivation $(51,62)$.

\section{Selective Estrogen Receptor Modulator}

The selective estrogen receptor modulator (SERMs) are agents that have the effect of estrogen antagonists on the target organ, and the agonistic effects on bones and blood vessels $(63,64)$. There are three types of SERM: triphenylethylene (tamoxifen), benzothiophene (raloxifen), and steroid (63). In animal models, raloxifene showed comparable benfits with anastrozole (AI) in reducing the size of lesion (65). In humans, the results are still unsatisfactory $(64,66)$. Newer generation SERM, bazedoxifen (BZA), is being extensively studied for endometriosis therapy $(47,64)$. The decrease in the size of lesions \& reduced expression of various genes involved in tissue proliferation are significantly found after the administration of BZA $3 \mathrm{mg} / \mathrm{kg} /$ day $(64,67)$. BZA administration alone ( $3 \mathrm{mg} / \mathrm{kg} /$ day) or BZA-conjugatedestrogen combination led to lesion size reduction and decreased ER expression (68).

\section{Selective Progesterone Receptor Modulator}

Selective progesterone receptor modulator (SPRMs) are PR ligands with specific clinical effects: agonists, antagonist, or agonist-antagonist combination on progesterone target tissues in vivo (69). The ideal SPRM for therapy is capable of triggering antiproliferative effects on the endometrium and breast, but retains the protective effects of estrogen on bone and cardiovascular systems (69-71). Histologic observation shows that SPRM administration results in reduced endometrial thickness, loss of mitotic activity, and increased stromal density $(71,72)$. In animals, SPRM does not produce ovarian estrogen production suppression. It seems like the suppressive effects are stronger on endometrial tissue compared to hypothalamus-pituitary-gonad axis (71).

Experimental study on primates by giving asoprisnil and asoprisnil ecamate, resulted in amenorrhoea, endometrial proliferative suppression, and endometrial atrophy (69). In phase II studies, asoprisnil of 5, 10 and $25 \mathrm{mg}$ doses significantly improved the non-menstrual pelvic pain scores $(69,73)$. In a study on rats, ulipristal administration reduced endometriotic focci by at least $50 \%$ and is associated with a decrease in the number of cells exhibiting proliferative activity $(70,74,75)$. In humans, administration of ulipristal acetate (doses 10, 50 or $100 \mathrm{mg}$ ) in the mid-luteal phase inhibits endometrial maturation, decreases endometrial thickness, and induces endometrial atrophy. Also, endometrial glands shows mixed secretory and proliferative characteristics $(76,77)$.

\section{Non-Invasive Therapy}

\section{High-Intensity Focused Ultrasound}

High-intensity focused ultrasound (HIFU) is a new technique that utilizes local heating phenomenon. This technique was first introduced by Zhang and Wang (78) in 1940 (79). Currently, HIFU can be performed with the guidance of ultrasound (USgHIFU) or magnetic resonance imaging (78). The physical basis of HIFU technique is by focusing the ultrasonic wave so that high intensity acoustic energy will be absorbed and then converted into heat at a designed focal point, resulting in thermal coagulation. Other mechanisms that may be involved are acoustic cavitation (interaction of sound waves with microscopic gas formation) and radiation forces (microflow of liquid around the bubbles) (80,81).

Abnormal tissue ablation with USgHIFU in the case of adenomyosis provides good safety and effectiveness as well as significant improvement of clinical symptoms (82). HIFU has also been proven effective for ablation of endometriotic lesions. In one study, cyclic pain disappeared in all patients after 3-31 months (mean 18.7 months) (83). Some of the HIFU weaknesses are as follow: 1) ultrasonic waves can not penetrate hollow viscera, 2) time-consuming in certain cases, 3) movement during procedure is not allowed, thus, it needs additional regional anesthesia, which is the policy in many centers (79). Severe complications ever reported are post-procedure vaginal bleeding, and unexplained tumor enlargement that causes discomfort (84).

Endometriosis is a gynecologic disorder highly associated with chronic pelvic pain and infertility. Dienogest, AI, and GnRH antagonists have been proven effective as endometriosis therapy in many clnical studies, with good tolerance and safety. Studies on SERM and SPRM are mostly still in phase I and II clinical trials, that show inconsistent results. AntiTNF- $\alpha$ is still studied in the animal model. HIFU is a potential futuristic treatment. However, it is still a long way until this technology is truly applicable.

Author Contributions: Concept-A.S.; Design-A.S.; Supervision - A.S.; Funding - T.G.A.P., A.S.; Materials - A.S.; Data Collection and/or Processing - T.G.A.P.; Analysis and/or Interpretation T.G.A.P.; Literature Review - T.G.A.P.; Writer - T.G.A.P.; Critical Review - A.S.

Conflict of Interest: No conflict of interest was declared by the authors. 


\section{Financial Disclosure: The authors declared that this study has} received no financial support.

\section{References}

1. Fritz MA, Speroff L. Clinical gynecologic endocrinology and infertility 8th ed. Lippincott Williams \& Wilkins; 2010.

2. Hickey M, Ballard K, Farquhar C. Endometriosis. BMJ 2014; 348: g1752.

3. Fadhlaoui A, Bouquet de la Jolinière J, Feki A. Endometriosis and infertility: how and when to treat? Front Surg 2014; 1: 24.

4. Fuldeore M, Yang H, Du EX, Soliman AM, Wu EQ, Winkel C. Healthcare utilization and costs in women diagnosed with endometriosis before and after diagnosis: a longitudinal analysis of claims databases. Fertil Steril 2015; 103: 163-71.

5. Practice Committee of the American Society for Reproductive Medicine. Endometriosis and infertility: a committee opinion. Fertil Steril 2012; 98: 591-8.

6. Suardika A. Endometriosis and infertility: diagnosis and treatment. Proceedings of the Professional Development on Infertility, Sanglah General Hospital, Bali, Indonesia 2014.

7. Sourial S, Tempest N, Hapangama DK. Theories on the pathogenesis of endometriosis. Int J Reprod Med 2014; 2014 179515.

8. Burney RO, Giudice LC. Pathogenesis and pathophysiology of endometriosis. Fertil Steril 2012; 98: 511-9.

9. Schrager S, Falleroni J, Edgoose J. Evaluation and treatment of endometriosis. Am Fam Physician 2013; 87: 107-13.

10. Marqui AB. Evaluation of endometriosis-associated pain and influence of conventional treatment: a systematic review. Rev Assoc Med Bras (1992) 2015; 61: 507-18.

11. Streuli I, de Ziegler D, Santulli P, Marcellin L, Borghese B, Batteux $F$, et al. An update on the pharmacological management of endometriosis. Expert Opin Pharmacother 2013; 14: 291-305.

12. Honda R, Katabuchi H. Pathological aspect and pathogenesis of endometriosis. Tokyo, Springer; 2014.

13. Schweppe KW, Rabe T, Langhardt M, Woziwodzki J, Petraglia F, Kiesel L. Endometriosis - pathogenesis, diagnosis, and therapeutic options for clinical and ambulatory care. J Reproduktionsmed Endokrinol 2013; 10: 102-19.

14. Reis FM, Petraglia F, Taylor RN. Endometriosis: hormone regulation and clinical consequences of chemotaxis and apoptosis. Hum Reprod Update 2013; 19: 406-18.

15. Macer ML, Taylor HS. Endometriosis and infertility: a review of the pathogenesis and treatment of endometriosis-associated infertility. Obstet Gynecol Clin North Am 2012; 39: 535-49.

16. Ahn SH, Monsanto SP, Miller C, Singh SS, Thomas R, Tayade C Pathophysiology and Immune Dysfunction in Endometriosis Biomed Res Int 2015; 2015: 795976.

17. Aznaurova YB, Zhumataev MB, Roberts TK, Aliper AM, Zhavoronkov AA. Molecular aspects of development and regulation of endometriosis. Reprod Biol Endocrinol 2014; 12: 50.

18. Dhesi AS, Morelli SS. Endometriosis: a role for stem cells. Womens Health (Lond) 2015; 11: 35-49.

19. Herington JL, Bruner-Tran KL, Lucas JA, Osteen KG. Immune interactions in endometriosis. Expert Rev Clin Immunol 2011; 7: 611-26.

20. Bulun SE, Cheng YH, Pavone ME, Xue Q, Attar E, Trukhacheva $\mathrm{E}$, et al. Estrogen receptor-beta, estrogen receptor-alpha, and progesterone resistance in endometriosis. Semin Reprod Med 2010; 28: 36-43.

21. Bulun SE. Endometriosis. N Engl J Med 2009; 360: 268-79.
22. Bulun SE, Monsavais D, Pavone ME, Dyson M, Xue Q, Attar E, et al. Role of estrogen receptor- $\beta$ in endometriosis. Semin Reprod Med 2012; 30: 39-45.

23. Maia H Jr, Haddad C, Coelho G, Casoy J. Role of inflammation and aromatase expression in the eutopic endometrium and its relationship with the development of endometriosis. Womens Health (Lond) 2012; 8: 647-58.

24. Soares SR, Martínez-Varea A, Hidalgo-Mora JJ, Pellicer A Pharmacologic therapies in endometriosis: a systematic review. Fertil Steril 2012; 98: 529-55.

25. Muñoz-Hernando L, Muñoz-Gonzalez JL, Marqueta-Marques L, Alvarez-Conejo C, Tejerizo-García Á, Lopez-Gonzalez G, et al. Endometriosis: alternative methods of medical treatment. Int $\mathrm{J}$ Womens Health 2015; 7: 595-603.

26. Mueck AO. Dienogest: an oral progestogen for the treatment of endometriosis. Expert Rev Obstet Gynecol 2011; 6: 5-15.

27. Schindler AE. Dienogest in long-term treatment of endometriosis. Int J Womens Health 2011; 3: 175-84.

28. Bizzarri N, Remorgida V, Leone Roberti Maggiore U, Scala C, Tafi E, Ghirardi V, et al. Dienogest in the treatment of endometriosis Expert Opin Pharmacother 2014; 15: 1889-902.

29. Ruan X, Seeger H, Mueck AO. The pharmacology of dienogest. Maturitas 2012; 71: 337-44.

30. Yamanaka K, Xu B, Suganuma I, Kusuki I, Mita S, Shimizu Y, et al. Dienogest inhibits aromatase and cyclooxygenase-2 expression and prostaglandin E2 production in human endometriotic stromal cells in spheroid culture. Fertil Steril 2012; 97: 477-82.

31. Harada T, Taniguchi F. Dienogest: a new therapeutic agent for the treatment of endometriosis. Womens Health (Lond) 2010; 6: 2735.

32. Hayashi A, Tanabe A, Kawabe S, Hayashi M, Yuguchi H, Yamashita $\mathrm{Y}$, et al. Dienogest increases the progesterone receptor isoform B/A ratio in patients with ovarian endometriosis. J Ovarian Res 2012; 5: 31

33. Suardika A. The provision of Dienogest in young women with endometriosis. Proceedings of the Seminar on Pelvic Pain. Bali Reproductive Endocrinology Association, Bali, Indonesia. 2015

34. Strowitzki T, Faustmann T, Gerlinger C, Schumacher U, Ahlers C, Seitz C. Safety and tolerability of dienogest in endometriosis: pooled analysis from the European clinical study program. Int $J$ Womens Health 2015; 7: 393-401.

35. Pavone ME, Bulun SE. Aromatase inhibitors for the treatment of endometriosis. Fertil Steril 2012; 98: 1370-9.

36. Nothnick WB. The emerging use of aromatase inhibitors for endometriosis treatment. Reprod Biol Endocrinol 2011; 9: 87.

37. Abu Hashim H. Potential role of aromatase inhibitors in the treatment of endometriosis. Int J Womens Health 2014; 6: 671-80.

38. Agarwal SK, Foster WG. Reduction in Endometrioma Size with Three Months of Aromatase Inhibition and Progestin Add-Back. Biomed Res Int 2015; 2015: 878517

39. Buzdar AU. Pharmacology and pharmacokinetics of the newer generation aromatase inhibitors. Clin Cancer Res 2003; 9: 468-72.

40. Ferrero S, Gillott DJ, Venturini PL, Remorgida V. Use of aromatase inhibitors to treat endometriosis-related pain symptoms: a systematic review. Reprod Biol Endocrinol 2011; 9: 89.

41. Ferrero S, Venturini PL, Gillott DJ, Remorgida V. Letrozole and norethisterone acetate versus letrozole and triptorelin in the treatment of endometriosis related pain symptoms: a randomized controlled trial. Reprod Biol Endocrinol 2011; 9: 88

42. Macer ML, Taylor HS. Endometriosis and infertility: a review of the pathogenesis and treatment of endometriosis-associated infertility Obstet Gynecol Clin North Am 2012; 39: 535-49. 
43. Polyzos NP, Fatemi HM, Zavos A, Grimbizis G, Kyrou D, Velasco JG, et al. Aromatase inhibitors in post-menopausal endometriosis. Reprod Biol Endocrinol 2011; 9: 90.

44. Ezzati M, Carr BR. Elagolix, a novel, orally bioavailable GnRH antagonist under investigation for the treatment of endometriosisrelated pain. Womens Health (Lond) 2015; 11: 19-28.

45. Tafi E, Leone Roberti Maggiore U, Alessandri F, Bogliolo S, Gardella B, Vellone VG, et al. Advances in pharmacotherapy for treating endometriosis. Expert Opin Pharmacother 2015; 16: 2465-83.

46. Lee DY, Park HG, Yoon BK, Choi D. Effects of different addback regimens on hypoestrogenic problems by postoperative gonadotropin-releasing hormone agonist treatment in endometriosis. Obstet Gynecol Sci 2016; 59: 32-8.

47. Carr B, Dmowski WP, O'Brien C, Jiang P, Burke J, Jimenez R, et al. Elagolix, an oral GnRH antagonist, versus subcutaneous depot medroxyprogesterone acetate for the treatment of endometriosis: effects on bone mineral density. Reprod Sci 2014; 21: 1341-51.

48. Melis GB, Neri M, Corda V, Malune ME, Piras B, Pirarba S, et al. Overview of elagolix for the treatment of endometriosis. Expert Opin Drug Metab Toxicol 2016; 12: 581-8.

49. Diamond MP, Carr B, Dmowski WP, Koltun W, O'Brien C, Jiang P, et al. Elagolix treatment for endometriosis-associated pain: results from a phase 2, randomized, double-blind, placebo-controlled study. Reprod Sci 2014; 21: 363-71.

50. Carr B, Giudice L, Dmowski WP, O'Brien C, Jiang P, Burke J, et al. Elagolix, an oral GnRH antagonist for endometriosisassociated pain: A randomized controlled study. Journal of Endometriosis 2013; 5: 105-15.

51. Lu D, Song H, Shi G. Anti-TNF- $\alpha$ treatment for pelvic pain associated with endometriosis. Cochrane Database Syst Rev 2013; CD008088.

52. Klotz U, Teml A, Schwab M. Clinical pharmacokinetics and use of infliximab. Clin Pharmacokinet 2007; 46: 645-60.

53. Jinesh S. Pharmaceutical aspects of anti-inflammatory TNFblocking drugs. Inflammopharmacology 2015; 23: 71-7.

54. Kondo W, dal Lago EA, Noronha Ld, Olandoski M, Kotze PG, Amaral VF. Effect of anti-TNF- $\alpha$ on peritoneal endometrial implants of rats Rev Col Bras Cir 2011; 38: 266-73.

55. Brown J, Farquhar C. Endometriosis: an overview of Cochrane Reviews. Cochrane Database Syst Rev 2014; CD009590.

56. Liu Y, Sun L, Hou Z, Mao Y, Cui Y, Liu J. rhTNFR: Fc Suppresses the Development of Endometriosis in a Mouse Model by Downregulating Cell Proliferation and Invasiveness. Reprod Sci 2016; 23: 847-57.

57. Yildirim G, Attar R, Ficicioglu C, Karateke A, Ozkan F, Yesildaglar $\mathrm{N}$. Etanercept causes regression of endometriotic implants in a rat model. Arch Gynecol Obstet 2011; 283: 1297-302.

58. Islimye M, Kilic S, Zulfikaroglu E, Topcu O, Zergeroglu S, Batioglu S. Regression of endometrial autografts in a rat model of endometriosis treated with etanercept. Eur J Obstet Gynecol Reprod Biol 2011; 159: 184-9.

59. Kyama CM, Overbergh L, Mihalyi A, Cuneo S, Chai D, Debrock S, et al. Effect of recombinant human TNF-binding protein-1 and GnRH antagonist on mRNA expression of inflammatory cytokines and adhesion and growth factors in endometrium and endometriosis tissues in baboons. Fertil Steril 2008; 89(5 Suppl): 1306-13.

60. Altan ZM, Denis D, Kagan D, Grund EM, Palmer SS, Nataraja SG. A long-acting tumor necrosis factor alpha-binding protein demonstrates activity in both in vitro and in vivo models of endometriosis. J Pharmacol Exp Ther 2010; 334: 460-6.

61. Zulfikaroglu E, Kılıc S, Islimye M, Aydin M, Zergeroglu S, Batioglu S. Efficacy of anti-tumor necrosis factor therapy on endometriosis in an experimental rat model. Arch Gynecol Obstet 2011; 283: 799804
62. Ceyhan ST, Onguru O, Fidan U, Ide T, Yaman H, Kilic S, et al. Comparison of aromatase inhibitor (letrozole) and immunomodulators (infliximab and etanercept) on the regression of endometriotic implants in a rat model. Eur J Obstet Gynecol Reprod Biol 2011; 154: 100-4.

63. Pinkerton JV, Thomas S. Use of SERMs for treatment in postmenopausal women. J Steroid Biochem Mol Biol 2014; 142: $142-54$.

64. Kulak J Jr, Fischer C, Komm B, Taylor HS. Treatment with bazedoxifene, a selective estrogen receptor modulator, causes regression of endometriosis in a mouse model. Endocrinology 2011; 152: 3226-32.

65. Altintas D, Kokcu A, Kandemir B, Tosun M, Cetinkaya MB. Comparison of the effects of raloxifene and anastrozole on experimental endometriosis. Eur J Obstet Gynecol Reprod Biol 2010; 150: 84-7.

66. Shang Y. Molecular mechanisms of oestrogen and SERMs in endometrial carcinogenesis. Nat Rev Cancer 2006; 6: 360-8.

67. Pluchino N, Freschi L, Wenger JM, Streuli I. Innovations in classical hormonal targets for endometriosis. Expert Rev Clin Pharmacol 2016; 9: 317-27.

68. Naqvi H, Sakr S, Presti T, Krikun G, Komm B, Taylor HS Treatment with bazedoxifene and conjugated estrogens results in regression of endometriosis in a murine model. Biol Reprod 2014; 90: 121.

69. Bouchard P, Chabbert-Buffet N, Fauser BC. Selective progesterone receptor modulators in reproductive medicine: pharmacology, clinical efficacy and safety. Fertil Steril 2011; 96: 1175-89.

70. Goyeneche AA, Telleria CM. Antiprogestins in gynecological diseases. Reproduction 2015; 149: 15-33.

71. Chwalisz K, Garg R, Brenner RM, Schubert G, Elger W. Selective Progesterone Receptor Modulators (SPRMs). Ann N Y Acad Sci 2002; 955; 373-88.

72. Chwalisz K, Brenner RM, Fuhrmann UU, Hess-Stumpp H, Elger W. Antiproliferative effects of progesterone antagonists and progesterone receptor modulators on the endometrium. Steroids 2000; 65: 741-51.

73. Chabbert-Buffet N, Pintiaux A, Bouchard P. The immninent dawn of SPRMs in obstetrics and gynecology. Mol Cell Endocrinol 2012; 358: $232-43$.

74. Huniadi CA, Antal TA, Stamatian F. The effects of ullipristal on surgically induced endometriosis in a rat model. Gynecology 2012; 28: 76-81.

75. Huniadi CA, Pop OL, Antal TA, Stamatian F. The effects of ulipristal on Bax/Bcl-2, cytochrome c, Ki-67 and cyclooxygenase-2 expression in a rat model with surgically induced endometriosis. Eur J Obstet Gynecol Reprod Biol 2013; 169: 360-5.

76. Mozzanega B, Gizzo S, Di Gangi S, Cosmi E, Nardelli GB. Ulipristal acetate: critical review about endometrial and ovulatory effects in emergency contraception. Reprod Sci 2014; 21: 678-85.

77. Zito G, Luppi S, Giolo E, Martinelli M, Venturin I, Di Lorenzo G, et al. Medical treatments for endometriosis-associated pelvic pain. Biomed Res Int 2014; 2014: 191967.

78. Zhang L, Wang ZB. High-intensity focused ultrasound tumor ablation: review of ten years of clinical experience. Front Med China 2014; 4: 294-302.

79. Mahmoud MZ, Alkhorayef M, Alzimami KS, Aljuhani MS, Sulieman A. High-Intensity Focused Ultrasound (HIFU) in Uterine Fibroid Treatment: Review Study. Pol J Radiol 2014; 79: 384-90.

80. Zhang L, Zhang W, Orsi F, Chen W, Wang Z. Ultrasound-guided high intensity focused ultrasound for the treatment of gynaecological diseases: A review of safety and efficacy. Int J Hyperthermia 2015; 31: $280-4$ 
81. Kim YS, Rhim H, Choi MJ, Lim HK, Choi D. High-intensity focused ultrasound therapy: an overview for radiologists. Korean J Radiol 2008; 9: 291-302.

82. Zhang X, Li K, Xie B, He M, He J, Zhang L. Effective ablation therapy of adenomyosis with ultrasound-guided high-intensity focused ultrasound. Int J Gynaecol Obstet 2014; 124: 207-11.
83. Wang Y, Wang W, Wang L, Wang J, Tang J. Ultrasound-guided high-intensity focused ultrasound treatment for abdominal wall endometriosis: preliminary results. Eur J Radiol 2011; 79: 56-9.

84. Kim HK, Kim D, Lee MK, Lee CR, Kang SY, Chung YJ, et al. Three cases of complications after high-intensity focused ultrasound treatment in unmarried women. Obstet Gynecol Sci 2015; 58: $542-6$. 